\title{
Vitamin D Status of Epileptic Children in India: A Prospective Cross-Sectional Study from a Tertiary Care Centre
}

\author{
Chandrika Azad ${ }^{1}$ Vishal Guglani ${ }^{1}$ Jasbinder Kaur ${ }^{2}$ Roosy Aulakh ${ }^{1}$ Sukhvinder Singh $^{3}$ \\ Sumiti Banga ${ }^{1}$
}

${ }^{1}$ Department of Pediatrics, Government Medical College and Hospital, Chandigarh, India

${ }^{2}$ Department of Biochemistry, Government Medical College and Hospital, Chandigarh, India

${ }^{3}$ Department of Medicine, H S Judge Institute of Dental Sciences, Punjab University, Chandigarh, India

J Child Sci 2020;10:e87-e92.

\begin{abstract}
Address for correspondence Chandrika Azad, MD, Department of Pediatrics, Government Medical College and Hospital, Chandigarh 160031, India (e-mail: chandrika_azad@yahoo.co.in).
\end{abstract}

\begin{abstract}
Keywords

- epilepsy

- children

- vitamin D deficiency

- antiepileptic drugs

Vitamin D deficiency is prevalent all over the world, especially in tropical countries. In epileptics, antiepileptic drugs (AED) and associated comorbidities further impact vitamin D status. The aim of this study is to estimate the prevalence of $25(\mathrm{OH})$ vitamin D deficiency in epileptic children and evaluate probable risk factors. A cross-sectional study of 200 children between 1 and 18 years of age on AED was undertaken in the pediatric neurology clinic of a tertiary care center of Northern India. In all children, serum $25(\mathrm{OH})$ vitamin D levels, calcium, phosphorus, and alkaline phosphatase were estimated. The deficiency levels of vitamin D were categorized as: deficiency $<20 \mathrm{ng} / \mathrm{mL}$, insufficiency 20 to $30 \mathrm{ng} / \mathrm{mL}$, and sufficiency $>30 \mathrm{ng} / \mathrm{mL}$. The potential risk factors for hypovitaminosis $D$, including type of epilepsy, AED regimen (specific medications, polytherapy vs. monotherapy), cerebral palsy, ambulatory status, intellectual disability, body mass index, gender, and vegetarianism were examined. Among the 200 enrolled children (60\% boys), 106/200 (53\%) were vitamin D deficient. There was no significant relation of vitamin D levels with gender, type of epilepsy, neurological deficit, and type of AED. An inverse relationship of higher phenytoin doses during monotherapy associated with lower vitamin D levels in monotherapy was found, thereby suggesting adverse effect of high doses of phenytoin on vitamin D levels. VDD is common among epileptic children on AED therapy. Vitamin D deficiency is common prevalent among epileptic children on AED therapy, and its detection and treatment correction should be an integral part of epilepsy management.
\end{abstract}

\section{Introduction}

Vitamin $D$ is an essential micronutrient for all age groups. Its deficiency not only leads to derangements in bone metabolism but also in other important functions such as immunity, cardiovascular health, cell differentiation and proliferation, etc. ${ }^{1,2}$ Vitamin D deficiency (VDD) is a global public-health concern. It is also highly prevalent in tropical regions where the risk of deficiency was previously assumed to be lower given longer sunlight. Various studies from India have shown received

February 7, 2020

accepted after revision

July 7,2020
DOI https://doi.org/

10.1055/s-0040-1715860. ISSN 2474-5871.
Copyright (c) 2020 Georg Thieme Verlag License terms KG Stuttgart · New York
(1) (1) 
a high prevalence of VDD among children. In a school-based study from New Delhi, around one-third of children were found to be severely deficient $(25(\mathrm{OH}) \mathrm{D}<9 \mathrm{ng} / \mathrm{mL}$ ), and this deficiency was more pronounced among females and those in lower socioeconomic status. ${ }^{3}$

The association between vitamin $\mathrm{D}$, antiepileptic drugs (AEDs) therapy, and bone health in individuals with epilepsy is well recognized. Although only few comparable studies are available in children, adults with epilepsy are known to be have and increased risk for bone fractures as compared with the general population. This risk increases with advancing age and duration of AED therapy. ${ }^{4,5}$ Chronic AEDs therapy adversely effects bone mineral metabolism and bone mineral density. ${ }^{6-8}$ The proposed mechanisms for adverse effects of AEDs on bone health are in part related to hepatic enzyme induction by AEDs, direct effect of the drug on intestinal calcium transport, impaired response to parathyroid hormone (phenobarbitone and phenytoin), secondary hyperparathyroidism, poor vitamin K status (phenytoin), and calcitonin deficiency. Multidrug AED therapy increases the risk for adverse bone health as compared with monotherapy. ${ }^{9}$

Poverty, low body mass index (BMI), and comorbidities (physical and mental handicap) place children with epilepsy on AEDs at higher risk for VDD and its consequences on bone health. The objective of this study was to describe the prevalence of VDD in children with epilepsy on AED therapy. Multidrug AED therapy increases the risk for adverse bone health as compared with monotherapy. ${ }^{9}$

\section{Methods}

\section{Study Design and Population}

This prospective single center cross-sectional study was conducted over a period of 1 year (August 2015-July 2016) at the Government Medical College and Hospital, a tertiary care hospital situated in the city of Chandigarh, Northern India. The study was cleared by the institutional ethics committee. Written informed consent was obtained from all the parents before subject recruitment.

\section{Inclusion and Exclusion Criteria}

Consecutive children with epilepsy between the ages of 1 and 18 years on AED therapy for $>3$ months, and presenting to the pediatric neurology clinic were included in the study. Children with suspected metabolic bone disorders or those whose parents declined consent/assent were excluded.

\section{Study Procedure and Data Collection}

Information regarding sociodemographic characteristics (age, gender, height, weight, and nutrition status) were collected via direct parent interview and physical examination of patient. Data were recorded in a structured case record form.

\section{Epilepsy: Definition and Types}

Epilepsy was defined as two or more unprovoked seizures occurring at an interval greater than 24 hours apart. Epilepsy was classified as per International League Against
Epilepsy (provide full name) 2017 classification. ${ }^{10}$ The underlying etiology was investigated with electroencephalography, neuroimaging (computed tomography scan and magnetic resonance imaging) and other relevant investigations.

\section{Antiepileptic Drug Classification}

AEDs were classified into two groups namely: "old AEDs" and "new AEDs." The old AED group included carbamazepine, clonazepam, ethosuximide, phenobarbital, phenytoin, and valproic acid. The new AED groups comprised of lamotrigine, levetiracetam, oxcarbazepine, topiramate, vigabatrin, zonisamide, felbamate, and gabapentin. Patients treated with more than one AED were classified as taking "old" AEDs if at least one of their prescribed medications fell into these categories.

\section{Risk Factors for Vitamin D Deficiency}

The potential risk factors for hypovitaminosis D included type of epilepsy, AED therapy characteristics (specific medications, polytherapy vs. monotherapy, and duration of treatment), cerebral palsy, ambulatory status, intellectual disability, BMI, gender, and vegetarianism were examined. BMI z-scores were taken as follows: $<-2$ z-score: thinning/moderate malnutrition, $<-3$ z-score: severe thinning/malnutrition, $>-2$ z-score and $<+2$ z-score: normal, $>2$ z-score: overweight, and $>3$ z-score: obese. For statistical analysis, $<-2$ and $<-3$ z-score were grouped together and $>+2$ and $>+3$ z-score together.

\section{Measurement and Definition of Vitamin D Levels}

At the time of enrolment, blood samples for $25(\mathrm{OH})$ vitamin D levels, serum calcium, phosphorus, and alkaline phosphatase levels were collected. Serum 25(OH) vitamin D levels were estimated by high performance liquid chromatography method. Vitamin D levels were categorized as: deficiency $<20 \mathrm{ng} / \mathrm{mL}$, insufficiency 20 to $30 \mathrm{ng} / \mathrm{mL}$, and sufficiency $>30 \mathrm{ng} / \mathrm{mL} .{ }^{11}$ For further analysis, children with insufficiency and sufficiency were grouped together in one group (nondeficient group), and children with deficiency were categorized in another group (deficient group). All children with VDD and insufficiency were treated with oral vitamin D and calcium supplementation.

\section{Measurement of Disability}

The functional mobility was measured on Gross Motor Function Classification System (GMFCS). The GMFCS is a five-level clinical classification system that describes the gross motor function of people with cerebral palsy on the basis of self-initiated movement abilities. ${ }^{12}$ Intelligence quotient (IQ) cutoff of $<70$ was used to define abnormal IQ.

\section{Socioeconomic Status}

Socioeconomic status was classified using the revised Kuppuswamy's Socioeconomic Status Scale. ${ }^{13}$ This scale helps assess socioeconomic status in hospital and communitybased studies in India, and takes into consideration the education status, the occupation of the head of the family, and the total family income. 


\section{Outcome Measures}

Primary outcome measures for the study were (1) proportion of children with $25(\mathrm{OH}) \mathrm{VDD}$ in the selected cohort of epileptic children, (2) proportion of children with VDD in various epilepsy groups as per the 2017 ILAE classification, and (3) association of 25(OH) vitamin D levels with doses of phenytoin, valproic acid, and carbamazepine in the monotherapy group.

\section{Statistical Methods}

Descriptive statistics was used to define demographic and baseline variables. Continuous data were presented as mean \pm standard deviation (SD) or median (interquartile range [IQR]) and dichotomous data as percentage. The distribution of the data was tested by Kolmogorov-Smirnov Test. The continuous data were compared by using Student's $t$-test for normally distributed data and Mann-Whitney test for skewed data. The dichotomous data were compared using Chi-square test or Fisher's exact test wherever applicable. Statistical analysis was done using SPSS window software, version 16.

\section{Results}

\section{Sociodemographic Characteristics}

A total of 200 patients were enrolled ( - Table 1 ). There were 119 (59.5\%) males and the median age was 10 years (IQR: 6-12 years). Only three (1.5\%) patients were nonambulatory. Majority of the patients (70\%) patients were natives of Chandigarh and neighboring areas and 122 (61\%) patients belonged to urban area. One hundred and seventy-six (80\%)

Table 1 Demographic and clinical features of children on antiepileptic drugs therapy

\begin{tabular}{|l|l|l|}
\hline & Variable & $\boldsymbol{n}(\%) \boldsymbol{n = 2 0 0}$ \\
\hline 1. & Age (y), mean \pm SD & $9.2 \pm 3.7$ \\
\hline 2. & Gender (males) & $119(59.5 \%)$ \\
\hline 3. & $\begin{array}{l}\text { Socioeconomic status } \\
\text { (Kuppuswamy IV and V) }\end{array}$ & $110(55 \%)$ \\
\hline 4. & Vegetarian food habits & $92(46 \%)$ \\
\hline 5. & $\begin{array}{l}\text { Vitamin D and calcium } \\
\text { supplementation }\end{array}$ & $195(97.5 \%)$ \\
\hline 6. & Native & $140(70 \%)$ \\
\hline 7. & Rural & $77(38.5 \%)$ \\
\hline 8. & BMI <-2 and -3 z-scores (wasting) & $78(39 \%)$ \\
\hline 9. & $\begin{array}{l}\text { BMI }>+2 \text { and }+3 \text { z-scores } \\
\text { (overweight and obesity) }\end{array}$ & $14(7 \%)$ \\
\hline 10. & VDD signs and symptoms & $3(1.5 \%)$ \\
\hline 11. & Neurological deficit & $27(13.5 \%)$ \\
\hline 12. & Abnormal IQ (<70) & $23(11.5 \%)$ \\
\hline 13. & Duration of epilepsy (mo) & $32 \pm 28.8$ \\
\hline 14. & Patients on monotherapy & $138(69 \%)$ \\
\hline 15. & Patients on polytherapy & $62(31 \%)$ \\
\hline
\end{tabular}

Abbreviations: BMI, body mass index; IQ, intelligent quotient; SD, standard deviation; VDD, vitamin D deficiency. patients belonged to Kuppuswamy III or IV (poor socioeconomic status). Approximately, half of the patients (92[46\%]) were lactovegetarians, while the rest of the patients took a similar diet with additional meat and eggs intake. Upon further inquiry, it was revealed that due to financial and religious constraints, nonvegetarian meal was possible only few times a month for most of the people. Only two (1\%) patients were tube fed.

The total sun exposure was on average 2 to 3 hours per day in $75 \%$ patients, and it varied by season and school timings. One hundred and eight children (54\%) had normal BMI, 38 (19\%) had malnutrition, and $7 \%$ were either overweight or obese ( - Table 2 ). In total, $5 \%$ had clinical features of rickets and $7 \%$ had megaloblastic anemia. None of the patients had fracture. Twenty-seven (13.5\%) patients had neurological deficit. The functional mobility was measured on GMFCS, majority had GMFCS level I, only $1.5 \%$ patients had GMFCS III or IV. All patients with high GMFCS score had cerebral palsy. Twenty-three (12\%) patients had IQ less than 70 (-Table 1).

\section{Epilepsy}

Median duration of epilepsy was 32 months $(\mathrm{SD}=28.8$ ) (-Table 1). As per the ILAE classification, 74 children (37\%) had generalized epilepsy, 119 (59.5\%) had focal epilepsy, two had combined, and five had unknown epilepsy. As per etiological classification, 95 had infectious, 71 genetic, 31 structural, and two unknown causes ( - Table 2 ).

\section{Antiepileptic Drugs}

\section{Vitamin D Status}

The mean dosing and duration of AEDs is shown in -Table 3. In total, 69\% (138/200) patients were on monotherapy. In the study group, valproic acid and carbamazepine were received for maximum duration. Very few patients received new AEDs.

Around $97.5 \%(n=195)$ patients received calcium and vitamin D supplementation (200-250 IU/day) during AED therapy, but none of the patient received treatment for VDD. Since Indian diet is deficient in calcium and vitamin D, many physicians associated with care of persons with epilepsy give routine calcium and vitamin $\mathrm{D}$, although there are no formal guidelines for it. Vitamin D was part of calcium syrup/tablet given to all patients and not as a separate supplementation.

A total of 106 (53\%) children had VDD. Only 22 (11\%) patients had vitamin D levels in sufficient range. Distribution of patients as per vitamin D levels is shown in - Table 4. The patients with vitamin D levels $>20 \mathrm{ng} / \mathrm{mL}$ were grouped together as nondeficient group. The mean vitamin $\mathrm{D}$ levels in deficient group was $13.33 \mathrm{ng} / \mathrm{mL}(\mathrm{SD}=5.00)$ and in nondeficient group $26.58 \mathrm{ng} / \mathrm{mL}(\mathrm{SD}=6.82)$. Among various age groups, VDD was significantly lesser in 1 to 5 year age group ( $p$-value $=0.002 ;$ - Table 2$)$. There was no statistically significant correlation of vitamin $D$ with vegetarian to nonvegetarian diet, place of origin, rural-urban habitation, socioeconomic status, and BMI. The VDD was seen in 15/27 (55\%) children with neurological deficit, which was comparable to children without neurological deficit (-Table 2 ). 
Table 2 Comparison of vitamin D deficient and nondeficient groups

\begin{tabular}{|c|c|c|c|c|c|}
\hline & & $n(\%)(n=200)$ & Vitamin D deficient $\boldsymbol{n}(\%)$ & Vitamin D nondeficient $\boldsymbol{n}(\%)$ & $p$-Value \\
\hline \multirow[t]{2}{*}{1.} & Gender (males) & 119 & $61(51)$ & $58(49)$ & \multirow[t]{2}{*}{0.67} \\
\hline & Females & 81 & $45(56)$ & $36(44)$ & \\
\hline \multirow[t]{3}{*}{2.} & $1-5$ years & 39 & $11(28)$ & $28(72)$ & \multirow[t]{3}{*}{0.002} \\
\hline & $6-10$ years & 74 & $42(56.7)$ & $32(43.2)$ & \\
\hline & $11-18$ years & 87 & $53(61)$ & $34(39)$ & \\
\hline \multirow[t]{2}{*}{3.} & Natives & 140 & $77(55)$ & $63(45)$ & \multirow[t]{2}{*}{0.38} \\
\hline & Migrants & 60 & $29(48.3)$ & $31(51.6)$ & \\
\hline \multirow[t]{2}{*}{4.} & Rural & 78 & $41(53)$ & $37(47)$ & \multirow[t]{2}{*}{0.95} \\
\hline & Urban & 122 & $65(53)$ & $57(47)$ & \\
\hline \multirow[t]{3}{*}{5.} & BMI $>-2$ and $<+2$ z-score & 108 & $61(56.5)$ & $47(43.5)$ & \multirow[t]{3}{*}{0.56} \\
\hline & $\mathrm{BMI}<-2$ z-score & 78 & $38(49)$ & $40(51)$ & \\
\hline & $\mathrm{BMI}>+2$ z-score & 14 & $7(50)$ & $7(50)$ & \\
\hline 6. & Cerebral palsy & 26 & $14(54)$ & $12(46)$ & 0.68 \\
\hline 7. & Neurological deficit & 27 & $15(55)$ & $12(45)$ & 0.48 \\
\hline 8. & Nonambulatory & 3 & $1(33)$ & $2(67)$ & \\
\hline \multirow[t]{2}{*}{9.} & Vegetarian & 92 & $46(50)$ & $46(50)$ & \multirow[t]{2}{*}{0.34} \\
\hline & Nonvegetarian & 108 & $60(56)$ & $48(44)$ & \\
\hline \multirow[t]{2}{*}{10.} & AED (monotherapy) & 138 & $74(53)$ & $64(47)$ & \multirow[t]{2}{*}{0.79} \\
\hline & AED (polytherapy) & 62 & $32(51.5)$ & $30(48.5)$ & \\
\hline \multirow[t]{2}{*}{11.} & Old AED & 198 & $105(53)$ & $93(47)$ & \multirow[t]{2}{*}{0.93} \\
\hline & New AED & 2 & $1(50)$ & $1(50)$ & \\
\hline \multirow[t]{5}{*}{12.} & Type of epilepsy & & & & \\
\hline & Generalized & 74 & $41(55)$ & $33(45)$ & \multirow[t]{4}{*}{0.65} \\
\hline & Focal & 119 & $62(52)$ & $57(48)$ & \\
\hline & Combined & 2 & $1(50)$ & $1(50)$ & \\
\hline & Unknown & 5 & $2(40)$ & $3(60)$ & \\
\hline \multirow[t]{5}{*}{13.} & Etiology of epilepsy & & & & \\
\hline & Structural & 31 & $17(55)$ & $14(45)$ & \multirow[t]{4}{*}{0.74} \\
\hline & Genetic & 71 & $40(56)$ & $31(44)$ & \\
\hline & Infectious & 95 & $48(50.5)$ & $47(49.5)$ & \\
\hline & Unknown & 2 & $1(50)$ & $1(50)$ & \\
\hline
\end{tabular}

Abbreviations: AED, antiepileptic drug; BMI, body mass index.

Table 3 Antiepileptic drugs dosage and their duration

\begin{tabular}{|l|l|l|l|}
\hline & $\boldsymbol{n}$ & $\begin{array}{l}\text { Dose } \\
(\mathrm{mg} / \mathrm{kg} / \text { day })\end{array}$ & $\begin{array}{l}\text { Duration } \\
(\mathbf{m o})\end{array}$ \\
\hline Carbamazepine & 33 & $13.13 \pm 3.10$ & $23(10-26)$ \\
\hline Levetiracetam & 10 & $21.22 \pm 13.67$ & $16.55 \pm 13.67$ \\
\hline Lamotrigine & 1 & 10.00 & 96 \\
\hline Clobazam & 13 & $0.377 \pm 0.22$ & $12.92 \pm 10.6$ \\
\hline Clonazepam & 2 & $0.42 \pm 0.45$ & 12 \\
\hline Phenobarbitone & 2 & $7.35 \pm 6.57$ & $10.5 \pm 10.60$ \\
\hline Phenytoin & 140 & $6 \pm 4.50$ & $20 \pm 10.5$ \\
\hline Sodium valproate & 71 & $40 \pm 18.90$ & $21 \pm 12.2$ \\
\hline
\end{tabular}

Table 4 Distribution of patients as per vitamin D levels

\begin{tabular}{|l|l|l|}
\hline $\begin{array}{l}\text { Serum 25 }(\mathrm{OH}) \\
\text { vitamin D } \\
\text { levels }(\mathbf{n g} / \mathrm{mL})\end{array}$ & $\begin{array}{l}\boldsymbol{n}(\%) \\
\boldsymbol{n}=\mathbf{2 0 0}\end{array}$ & Mean \pm SD (range) \\
\hline$<20$ (deficiency) & $106(53 \%)$ & $\begin{array}{l}13.33 \pm 5.00 \\
(4.20-19.93)\end{array}$ \\
\hline $20-30$ (insufficiency) & $72(36 \%)$ & $\begin{array}{l}23.43 \pm 2.50 \\
(20.14-29.90)\end{array}$ \\
\hline$>30$ (sufficiency) & $22(11 \%)$ & $\begin{array}{l}36.89 \pm 6.30 \\
(30.13-49.22)\end{array}$ \\
\hline Total & 200 & $\begin{array}{l}19.55 \pm 8.88 \\
(4.20-49.22)\end{array}$ \\
\hline
\end{tabular}


In the monotherapy group, $74 / 138$ (54\%) children had vitamin D in deficient range, while $32 / 62$ (51.5\%) were vitamin $\mathrm{D}$ deficient in the polytherapy group $(p=0.79)$. In the old AED group, 105/198 (53\%) were deficient. Although 11 children were on new AEDs (levetiracetam $=10$, lamotrigine $=1$ ), but only two patients were classified into new AED group as one or more old AED was being given concomitantly (-Table 2). Increase in phenytoin dose was associated with a decrease in vitamin D levels in the monotherapy group, whereas this effect was not seen in the polytherapy group. No other AED in old and new group had significant correlation with vitamin D levels. On comparing long monotherapies (phenytoin, valproate, and carbamazepine) on one-way ANOVA, no statistically significant difference was noted between the group means of vitamin D levels (f-ratio value of 0.65422 and $p$-value of 0.52 ).

Majority of the children in deficient group (93.4\%) had normal serum calcium levels and only $1.9 \%$ of patients had a serum calcium levels of $<8 \% \mathrm{mg}$. Both the groups had only two patients with hypocalcemia, whereas 14 in the sufficient group as compared with five in the deficient group had higher serum calcium ( $p=0.048)$. There was no significant difference in serum phosphorus levels between the two groups.

\section{Discussion}

The present study showed a high prevalence (53\%) of VDD in epileptic children, and very few children (11\%) had vitamin D in the sufficient range. Majority of patients (80\%) belonged to poor socioeconomic status. However, the study found no significant relation to type of epilepsy and AED, dietary preferences, socioeconomic status, and gender with VDD. In children between 1 and 5 years of age, VDD was less common, whereas in older age group (11-18 years) VDD was significantly higher which might be related to the longer duration of therapy and underlying disability. Among AED, patients with higher doses of phenytoin had lower vitamin D levels in the monotherapy group suggesting its dose-related adverse effect on bone metabolism. The VDD noted despite adequate sun exposure in Indian subcontinent is not a surprising finding due to the abundance of melanin and others factors. Fong et al have reported a high incidence of VDD in epileptic children from Australia and Malaysia. ${ }^{14,15}$ The risk factors identified were multiple AEDs, genetic factors, low sun exposure time, ethnicity, and female gender.

Lee et al, in a longitudinal study, noted that a large proportion of patients on AED develops significant decrease in vitamin D levels during follow-up. They identified poly- therapy, prolonged AED therapy, tube feeding, and overweight as independent risk factors for this decrease. ${ }^{16}$ They recommended continued vigilance and vitamin D supplementation during AED therapy.

Many AEDs are inducers of hepatic CYP450 metabolism. It has been postulated that these AEDs increase hepatic metabolism of vitamin $\mathrm{D}$, which leads to abnormally enhanced bone turnover. ${ }^{9}$ However, no enzyme-inducing AEDs (e.g., valproic acid) are also associated with poor bone health. ${ }^{10}$ Although the newer AEDs (e.g., lamotrigine, levetiracetam, and oxcarbazepine) are less-potent enzyme inducers than carbamazepine or phenytoin, they are not necessarily inert in bone metabolism. Various studies from across the globe have found association of AED with lower vitamin D levels. Two recent studies from India in children have reported a significant association of VDD with carbamazepine and valproic acid therapy. ${ }^{17,18}$ Shellhaas et al reported a $25 \%$ incidence of VDD in their children in an outpatient clinic setting, though they found no significant association with the type of AED therapy. ${ }^{8}$ In our study, higher doses of phenytoin were associated with lower vitamin D levels. In a study from Iran, children with cerebral palsy showed a higher incidence of VDD as compared with the healthy population. ${ }^{19}$ In the present study, no significant difference was found between children with neurological deficit and their ambulatory status. This may be related to a higher incidence of VDD in the general population and vitamin D supplementation given to all epileptic children and as a result minimizing the difference between the two groups. Prolonged AED therapy impairs bone health during childhood during a period of high bone mineral deposition. Thus, a weak bone structure in the setting of seizures with major motor manifestations, impaired motor function, and coordination can predispose to fractures. ${ }^{5}$ In the present study, none of the patients developed fractures. The literature shows that patients on AED may have adverse effects on bone mineral density with or without associated VDD. 6,20

Harijan et al reviewed various studies on vitamin D supplementation in epileptic children and found inconsistent results among the studies and emphasized on the need for larger studies with the inclusion of clinically significant outcomes such as fractures. It also suggested to, include at risk populations such as symptomatic generalized epilepsy, those with impaired mobility, and the effects of AED polytherapy. Given the risk of poor bone health in epileptic children on AED therapy, the authors recommended vitamin D supplementation despite conflicting results from current studies. $^{21}$

Table 5 Comparison with existing literature

\begin{tabular}{|c|c|c|c|c|}
\hline Study (year) & Number of subjects & Age group & Vitamin D levels & $p$-Value \\
\hline Marwaha et $\mathrm{al}^{3}$ (2015) & 760 & \multirow[t]{2}{*}{$10-18$ years } & $11.8 \pm 7.20 \mathrm{ng} / \mathrm{mL}$ & \multirow[t]{2}{*}{$<0.001$} \\
\hline Present study & 108 & & $18.05 \pm 7.64 \mathrm{ng} / \mathrm{mL}$ & \\
\hline Basu et $\mathrm{al}^{22}(2015)$ & 310 & \multirow[t]{2}{*}{$1-16$ years } & $19 \mathrm{ng} / \mathrm{mL}$ (IQR: 11-28) & \multirow[t]{2}{*}{0.72} \\
\hline Present study & 198 & & $19.3 \mathrm{ng} / \mathrm{mL}$ (IQR: 13.6-23.8) & \\
\hline
\end{tabular}

Abbreviation: IQR, interquartile range. 
There are very few large-scale investigations on VDD in normal Indian children. Marwaha et al in their community survey in Delhi found mean 25(OH) vitamin D levels of $11.8 \pm 7.20 \mathrm{ng} / \mathrm{mL}$ which were significantly lower than our study, whereas Basu et al-in a hospital-based study from Kolkata-found that the mean $25(\mathrm{OH})$ vitamin D levels to be $19 \mathrm{ng} / \mathrm{mL}$ (IQR: 11-28) which were comparable to our study (-Table 5). ${ }^{3,22}$ Despite the associated risk factors for hypovitaminosis, we report higher mean vitamin D levels compared with Marwaha et al. It can be speculated that these differences may be related to either genetic differences in the patient population or the higher pollution levels in Delhi hampering vitamin D synthesis. ${ }^{23}$ Higher vitamin D levels in study by Basu et al could also be due to consumption of fish-based diet in these geographical areas. Higher or comparable vitamin D levels in our study might be because of vitamin D supplementation, although it did not correct deficiency state. This further emphasizes that testing to assess VDD should be undertaken in children with epilepsy instead of routinely supplementation with vitamin D.

\section{Conclusion}

VDD is common among epileptic children on AED therapy. Apart from regular vitamin D and calcium supplementation, emphasis should also be on the detection and correction of deficiency state.

\section{Funding}

This research project was funded by the Department of Science and Technology, Chandigarh, India.

\section{Conflict of Interest}

None declared.

\section{References}

1 Misra M, Pacaud D, Petryk A, Collett-Solberg PF, Kappy MDrug and Therapeutics Committee of the Lawson Wilkins Pediatric Endocrine Society. Vitamin D deficiency in children and its management: review of current knowledge and recommendations. Pediatrics 2008;122(02):398-417

2 Rovner AJ, O'Brien KO. Hypovitaminosis D among healthy children in the United States: a review of the current evidence. Arch Pediatr Adolesc Med 2008;162(06):513-519

3 Marwaha RK, Tandon N, Reddy DRHK, et al. . Vitamin D and bone mineral density status of healthy schoolchildren in northern India. Am J Clin Nutr 2005;82(02):477-482

4 Pack AM, Morrell MJ, Randall A, McMahon DJ, Shane E. Bone health in young women with epilepsy after one year of antiepileptic drug monotherapy. Neurology 2008;70(18):1586-1593

5 Shellhaas RA, Barks AK, Joshi SM. Prevalence and risk factors for vitamin D insufficiency among children with epilepsy. Pediatr Neurol 2010;42(06):422-426
6 Farhat G, Yamout B, Mikati MA, Demirjian S, Sawaya R, El-Hajj Fuleihan G. Effect of antiepileptic drugs on bone density in ambulatory patients. Neurology 2002;58(09):1348-1353

7 Sheth RD, Binkley N, Hermann BP. Progressive bone deficit in epilepsy. Neurology 2008;70(03):170-176

8 Menon B, Harinarayan CV. The effect of anti epileptic drug therapy on serum 25-hydroxyvitamin D and parameters of calcium and bone metabolism-a longitudinal study. Seizure 2010;19(03): 153-158

9 Valsamis HA, Arora SK, Labban B, McFarlane SI. Antiepileptic drugs and bone metabolism. Nutr Metab (Lond) 2006;3(01):36

10 Scheffer IE, Berkovic S, Capovilla G, et al. . ILAE classification of the epilepsies: position paper of the ILAE commission for classification and terminology. Epilepsia 2017;58(04):512-521

11 Holick MF, Binkley NC, Bischoff-Ferrari HA, et al; Endocrine Society. Evaluation, treatment, and prevention of vitamin D deficiency: an endocrine society clinical practice guideline. J Clin Endocrinol Metab 2011;96(07):1911-1930

12 Paulson A, Vargus-Adams J. Overview of four functional classification systems commonly used in cerebral palsy. Children (Basel) 2017;4(04):E30

13 Khairnar MR, Wadgave U, Shimpi PV. Kuppuswamy's socio-economic status scale: a revision of occupation and income criteria for 2016. Indian J Pediatr 2017;84(01):3-6

14 Fong CY, Kong AN, Poh BK, et al. Vitamin D deficiency and its risk factors in Malaysian children with epilepsy. Epilepsia 2016;57 (08):1271-1279

15 Fong CY, Riney CJ. Vitamin D deficiency among children with epilepsy in South Queensland. J Child Neurol 2014;29(03): 368-373

16 Lee Y-J, Park KM, Kim YM, Yeon GM, Nam SO. Longitudinal change of vitamin D status in children with epilepsy on antiepileptic drugs: prevalence and risk factors. Pediatr Neurol 2015;52(02): 153-159

17 Sreedharan M, Devadathan K, Mohammed Kunju PA, et al. Vitamin D deficiency in ambulant children on carbamazepine or sodium valproate monotherapy. Indian Pediatr 2018;55(04): 307-310

18 Chaudhuri JR, Mridula KR, Rathnakishore C, Balaraju B, Bandaru VS. Association of 25-hydroxyvitamin D deficiency in pediatric epileptic patients. Iran J Child Neurol 2017;11(02):48-56

19 Toopchizadeh V, Barzegar M, Masoumi S, Jahanjoo F. Prevalence of vitamin D deficiency and associated risk factors in cerebral palsy a study in north-west of Iran. Iran J Child Neurol 2018;12(02): 25-32

20 Vestergaard P. Effects of antiepileptic drugs on bone health and growth potential in children with epilepsy. Paediatr Drugs 2015; 17(02):141-150

21 Harijan P, Khan A, Hussain N. Vitamin D deficiency in children with epilepsy: do we need to detect and treat it? J Pediatr Neurosci 2013;8(01):5-10

22 Basu S, Gupta R, Mitra M, Ghosh A. Prevalence of vitamin d deficiency in a pediatric hospital of eastern India. Indian $\mathrm{J} C$ lin Biochem 2015;30(02):167-173

23 Mousavi SE, Amini H, Heydarpour P, Amini Chermahini F, Godderis L. Air pollution, environmental chemicals, and smoking may trigger vitamin D deficiency: evidence and potential mechanisms. Environ Int 2019;122:67-90 